\title{
Oral health status and related quality of life among tobacco factory and cotton ginning mill workers in Guntur city, Andhra Pradesh, India
}

\author{
Anusha Divvi ${ }^{1}$, Preetha Elizabeth Chaly², Shyam Sivasamy ${ }^{2}$, Junaid Mohammed ${ }^{3}$, Edward J. Nijesh ${ }^{2}$, Shivashankar \\ Kengadaran $^{1}$, Vaishnai Selvaperumal ${ }^{2}$
}

\author{
AFFILIATION \\ 1 Indira Gandhi Institute of Dental Sciences, Puducherry, India \\ 2 Meenakshi Ammal Dental College, Chennai, India \\ 3 The University of Western Australia, Crawley, Australia
}

CORRESPONDENCE TO

Anusha Divvi. Indira Gandhi Institute of Dental Sciences,

Pillayarkuppam, Puducherry 607402, India.

E-mail: anushadivvi1991@gmail.com

\section{KEYWORDS}

oral health status, oral health-related quality of life, tobacco factory workers

Received: 26 February 2019, Revised: 18 October 2019, Accepted: 25 October 2019

\begin{abstract}
INTRODUCTION The study was carried out to assess and compare the oral health status and oral health-related quality of life among tobacco factory workers and cotton ginning mill workers in Guntur city, Andhra Pradesh, India.

METHODS A cross-sectional study was carried among 160 tobacco factory workers and 160 cotton ginning mill workers aged 25-55 years. A simple random sampling methodology was used. The data were collected using a questionnaire and clinical examination. The questionnaire gathered information on demographic factors, factors related to the working environment, adverse habits of the study subjects and oral health-related quality of life using Oral Health Impact Profile-14 (OHIP-14). The subjects were clinically examined to assess their oral health status using WHO Oral Health Assessment Form (2013).

RESULTS The prevalences among tobacco factory workers and among cotton ginning mill workers, respectively, were: tobacco chewing habit $38.1 \%$ and $15 \%$; periodontal
\end{abstract}

pockets $47.5 \%$ and $31.25 \%$; loss of attachment $56.8 \%$ and 28.7\%; oral mucosal lesions $13.8 \%$ and $3.8 \%$; while the corresponding mean OHIP-14 scores were $20.81 \pm 11.59$ and $16.29 \pm 9.67$. All results were found to be significantly higher among tobacco factory workers compared to cotton ginning mill workers $(p<0.05)$. All the domains of OHIP14 were found to have a very high statistically significant positive correlation with DMFT, DMFS, periodontal pocket depth and loss of attachment in both study groups $(\mathrm{p}<0.001)$. The availability of tobacco in the workplace was found to be a significant barrier to quit tobacco among tobacco factory workers.

CONCLUSIONS The prevalence of periodontal diseases, oral mucosal lesions, use of tobacco and the OHIP-14 scores were all found to be significantly higher among tobacco factory workers compared to cotton ginning mill workers. OHIP-14 scores correlated significantly with clinical oral health status indicators in both study groups.

\section{INTRODUCTION}

Worldwide, one in ten deaths is caused by tobacco. During the last century, the number of people dying from tobacco was approximately 100 million, this is expected to rise to one billion deaths during the 21st century ${ }^{1}$. The driving force behind the tobacco epidemic is the trans-national tobacco industry. India is the third largest producer of tobacco in the world. Andhra Pradesh is first in tobacco production with an average yield of around 193.26 million kg per year, of which
154.07 million $\mathrm{kg}$ are exported ${ }^{2}$.

The occupation in which people engage and its related conditions have long been known to influence oral health and in turn the overall health and wellbeing of individuals ${ }^{3}$. The reason for poor oral health in many occupations can be attributed to the work environment. Previous research has found a strong association between oral diseases and physical/psychological afflictions arising from the workload and other factors related to the workplace ${ }^{4,5}$. 
Like cigarette smoking and other forms of tobacco use, working in the tobacco industry also leads to the intake of many hazardous compounds and their metabolites. These hazardous substances may react with organic molecules and lead to the formation of reactive oxygen species (ROS) that give rise to oxidative stress within the human body. Apart from causing illness and premature death, tobacco production results in other negative consequences such as economic loss for countries, poverty for individuals, deforestation and other environmental problems in countries growing tobacco ${ }^{6}$.

Oral diseases are a significant public health burden worldwide but often are given inadequate attention in many low- and middle-income countries, especially in India ${ }^{7}$. Oral diseases affect people's everyday lives subtly but pervasively, disrupting eating, sleep, work and social roles. Oral health is essential to overall health, well-being and quality of life ${ }^{8}$. Review of existing literature has shown that oral health status and related quality of life of tobacco factory workers are not adequately documented. Since, Guntur city, the administrative capital of Guntur district, is acclaimed for its export industries, which include tobacco factories and cotton ginning mills, the workers of cotton ginning mills were considered as a suitable comparison group.

While tobacco factory workers have ready access to tobacco and are exposed to it on a daily basis at their workplace, the cotton ginning mill workers are strictly prohibited from using smoking tobacco products within the factory premises. It can be contemplated that the varying environment that exists in their workplace can affect their oral health status and thus oral health quality of life in the long-term. Hence, the main objective of the present study was to test the hypothesis that oral health status and related quality of life among the workers in tobacco factories are poorer compared to workers in cotton ginning mills.

\section{METHODS}

This cross-sectional study was carried out among workers of cotton ginning mills and tobacco factories in Guntur city, Andhra Pradesh, India. A detailed protocol explaining the nature and purpose of the study was submitted to the Institutional Review Board, and after its scrutiny, ethical clearance was obtained (MADC/IRB-IX/2016/185). The list of tobacco factories and cotton ginning mills located in Guntur city was collected from the State Tobacco Board and Cotton Ginning Mill Association of Guntur district, respectively. The nature and purpose of the study were explained to the administrators of the selected factories. Permission was then obtained to conduct the study in their premises among their factory workers. Informed consent was obtained from the study subjects (Supplementary file).

We used a specially designed proforma to collect data on demographic details, a questionnaire regarding information on work environment, adverse habits, oral health status and related quality of life. Demographic details included age, gender, education and occupation. The questionnaire
(Supplementary file) consisted of ten open-ended questions on factors related to work and adverse habits. Data such as average working hours per day (item 2), use of protective wear during work (item 3), frequency of smoking per week (item 5), frequency of chewing tobacco per week (item 7), previous history of attempting to quit the use of tobacco products (item 9), awareness regarding ill effects of tobacco use (item 8) and their perception of working place as a barrier to quit tobacco use (item 10) were recorded.

We used questionnaire on Oral Health Impact Profile-14 (OHIP-14) to assess the oral health-related quality of life 9 . The responses were coded as 'never' (0), 'hardly' (1), 'occasionally' (2), 'fairly often' (3), and 'very often' (4). The total OHIP-14 score was calculated by summing responses to all 14 items, with possible scores ranging from 0 to 56; wherein the higher the OHIP-14 score, the poorer the oral health quality of life. Additionally, the answers to each question of OHIP-14 were dichotomized, and the presence of impact was defined by the answers 'fairly often' and 'very often', and for those without impact, by the answers 'occasionally', 'hardly' and 'never'. In order to achieve culturally acceptable and conceptually equivalent OHIP14, specific guidelines for cross-cultural adaptation were followed. The English version of OHIP-14 was translated to Telugu by two independent translators. A single translated version was developed with consensus from both translators, which was then back-translated into English by two independent translators. An expert committee consisting of all the translators and a public health dentist was then formed to develop the final version of Telugu OHIP-14. The responses for the Telugu OHIP-14 were similar to that of the English version. Face-to-face interviews with the translated version were conducted among 40 outpatients to assess the content validity of the translated questionnaire.

Test-retest reliability was evaluated using the Intra-class Correlation Coefficient (ICC). The percentage variation in response was calculated to determine whether a change in scores had occurred during the retest period. An acceptable ICC score of 0.82 was obtained for the questionnaire on OHIP-14.

Subjects were seated comfortably on an ordinary chair and examined in their respective workplace under natural light and positioned so as to receive maximum illumination. ADA type III examination technique was used wherein oral examinations were conducted using a plane mouth mirror and a WHO probe. Dentition status by tooth surface, gingival bleeding, pockets, loss of attachment, enamel fluorosis severity, dental erosion, dental trauma, oral mucosal lesions, denture status and intervention urgency were recorded using the WHO Oral Health Assessment Form 2013 by a single well-trained examiner ${ }^{10}$. Following the training session, the WHO form was recorded for the same group of randomly selected twenty-five hospital employees on successive days. The intra-examiner reliability was assessed using Cronbach's alpha and found to be between $0.85-0.93$ for various clinical parameters. 
A pilot study was then carried out among randomly selected fifty tobacco factory workers and fifty cotton mill workers, to assess the feasibility of the study and to estimate the sample size for the main study. The sample size for the main study was calculated using sampling software (G power version 3.1.9.2, Heinrich-Heine-Universitat, Dusseldorf, Germany) based on the difference in the overall scores of Oral Health Impact Profile-14 between tobacco factory workers and cotton ginning mill workers. The final sample for the study was calculated to be 320 (effect size $=0.4398850, \alpha=5 \%$, power=95\%) with 160 in each group and a simple random sampling methodology was used to recruit the required number of study subjects.

The collected data were analysed using the Statistical Package for Social Sciences (SPSS) version 20.0. Descriptive statistics such as frequency, percentage, mean and standard deviation were calculated. The quantitative variables were assessed for normality using Shapiro-Wilk test, and the data were found to be normal ( $p>0.05)$. Intergroup analysis for parametric data was carried out using independent sample t-test. The qualitative data in the present study were assessed for statistical significance using Pearson's chisquared test. Correlation between DMFT score, periodontal pocket depth, loss of attachment and OHIP-14 were carried out using Spearman's rank order correlation coefficient test. A $p<0.05$ was considered as statistically significant.

\section{RESULTS}

The distribution of the workers based on demographic factors in the two study groups is compared and presented in Table 1. The distribution of workers based on the factors related to their own working environment and adverse habits is presented in Table 2. There were no statistically significant differences in the distribution of study subjects between the two groups based on age group, gender, duration of employment, use of smoking form of tobacco and with respect to the use of protective mask ( $p>0.05$ ).

Table 1. Distribution of workers based on demographic factors in the two study groups

\begin{tabular}{|l|c|c|c|}
\hline Demographic variable & $\begin{array}{c}\text { Tobacco } \\
\text { factory } \\
\text { workers } \\
\text { n (\%) }\end{array}$ & $\begin{array}{c}\text { Cotton } \\
\text { ginning mill } \\
\text { workers } \\
\text { n (\%) }\end{array}$ & $\mathbf{p}^{\mathrm{a}}$ \\
\hline Gender & $82(51.2)$ & $81(50.6)$ & $0.91^{\mathrm{b}}$ \\
\hline Male & $78(48.8)$ & $79(49.4)$ & \\
\hline Female & & & \\
\hline Age group (years) & $47(29.3)$ & $48(30.0)$ & \\
\hline $25-35$ & $54(33.8)$ & $54(33.8)$ & $0.99^{\mathrm{b}}$ \\
\hline $36-45$ & $59(36.9)$ & $58(36.2)$ & \\
\hline $46-55$ & &
\end{tabular}

a Pearson's chi-squared test. $\mathrm{b}$ p $>0.05$ is not significant.
Table 2. Distribution of workers based on factors related to working environment and adverse habits

\begin{tabular}{|c|c|c|c|}
\hline $\begin{array}{l}\text { Factors related to work } \\
\text { and tobacco habits }\end{array}$ & $\begin{array}{c}\text { Tobacco } \\
\text { factory } \\
\text { workers } \\
\text { n (\%) }\end{array}$ & $\begin{array}{c}\text { Cotton } \\
\text { ginning } \\
\text { mill } \\
\text { workers } \\
\text { n (\%) }\end{array}$ & $\mathbf{p}^{\mathrm{a}}$ \\
\hline \multicolumn{4}{|l|}{ Years of employment } \\
\hline $1-5$ & $38(23.8)$ & $28(17.5)$ & \multirow{3}{*}{$0.38^{b}$} \\
\hline $6-10$ & $56(35.0)$ & $60(37.5)$ & \\
\hline$>10$ & $66(41.2)$ & $72(45.0)$ & \\
\hline \multicolumn{4}{|l|}{ Working hours per day } \\
\hline$<8$ & $20(12.5)$ & $0(0)$ & \multirow{3}{*}{$<0.001$} \\
\hline $8-10$ & $97(60.6)$ & $137(85.6)$ & \\
\hline$>10$ & $43(26.9)$ & $23(14.4)$ & \\
\hline \multicolumn{4}{|l|}{ Use of mask } \\
\hline Yes & 3 (1.9) & $4(2.5)$ & \multirow{2}{*}{0.702} \\
\hline No & $157(98.1)$ & $156(97.5)$ & \\
\hline \multicolumn{4}{|l|}{ Smoking habit } \\
\hline Yes & $41(25.6)$ & $36(22.5)$ & \multirow{2}{*}{$0.60^{\mathrm{b}}$} \\
\hline No & $119(74.4)$ & $124(77.5)$ & \\
\hline \multicolumn{4}{|l|}{$\begin{array}{l}\text { Frequency of smoking } \\
\text { tobacco }\end{array}$} \\
\hline $\begin{array}{l}\text { More than } 4 \text { times per } \\
\text { week }\end{array}$ & $38(92.7)$ & $27(75)$ & \multirow[t]{2}{*}{0.066} \\
\hline Irregularly & $3(7.3)$ & $9(25)$ & \\
\hline \multicolumn{4}{|l|}{ Tobacco chewing habit } \\
\hline Yes & $61(38.1)$ & 24 (15) & \multirow{2}{*}{$<0.001$} \\
\hline No & $99(61.9)$ & $136(85)$ & \\
\hline
\end{tabular}

Frequency of chewing

tobacco

\begin{tabular}{|c|c|c|c|}
\hline More than twice a week & $1(1.6)$ & $2(8.4)$ & \multirow{3}{*}{$<0.001^{\mathrm{c}}$} \\
\hline $\begin{array}{l}\text { More than } 4 \text { times a } \\
\text { week }\end{array}$ & $58(95.1)$ & 7 (29.1) & \\
\hline Irregularly & $2(3.3)$ & $15(62.5)$ & \\
\hline \multicolumn{4}{|l|}{$\begin{array}{l}\text { Awareness on ill effects of } \\
\text { tobacco }\end{array}$} \\
\hline Yes & $150(93.8)$ & $160(100)$ & \multirow{2}{*}{$0.002^{c}$} \\
\hline No & $10(6.2)$ & $0(0)$ & \\
\hline \multicolumn{4}{|l|}{ Attempted to quit tobacco } \\
\hline Yes & 67 (89.3) & 66 (97.1) & \multirow{2}{*}{$0.101^{\mathrm{b}}$} \\
\hline No & 8 (10.7) & $2(2.9)$ & \\
\hline \multicolumn{4}{|l|}{$\begin{array}{l}\text { Felt working environment } \\
\text { as barrier to quit habit }\end{array}$} \\
\hline Yes & $56(74.7)$ & $7(10.3)$ & \multirow{2}{*}{$<0.001^{\mathrm{c}}$} \\
\hline No & $19(25.3)$ & 61 (89.7) & \\
\hline
\end{tabular}

a Pearson's chi-squared test. $b$ p $>0.05$ is not significant. c $p>0.05$ is not significant 
Figure 1. Prevalence of oral health related conditions among study subjects

口Tobacco factory workers $\square$ Cotton ginning mill workers

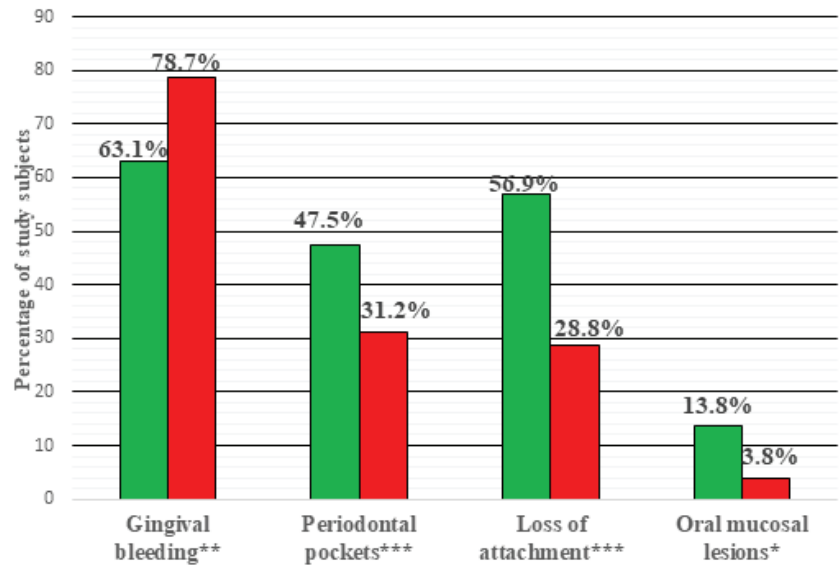

Pearson's chi-squared test was used to compare the prevalence of various oral conditions among the workers.

${ }^{*} \mathrm{p}<0.05 .{ }^{* *} \mathrm{p}<0.01 .{ }^{* * *} \mathrm{p}<0.001$.

Table 3. Comparison of frequency of impact for each 0HIP-14 domain between the workers in two groups

\begin{tabular}{|l|c|c|c|} 
OHIP-14 Domains & $\begin{array}{c}\text { Frequency } \\
\text { of impact } \\
\text { among } \\
\text { tobacco } \\
\text { factory } \\
\text { workers } \\
\text { n (\%) }\end{array}$ & $\begin{array}{c}\text { Frequency } \\
\text { of impact } \\
\text { among } \\
\text { cotton } \\
\text { ginning } \\
\text { mill } \\
\text { workers } \\
\text { n (\%) }\end{array}$ & \multirow{2}{*}{$\mathbf{p}^{\mathrm{a}}$} \\
\hline Functional limitation & $9(5.62)$ & $1(0.62)$ & $0.010^{\mathrm{b}}$ \\
Physical pain & $26(16.25)$ & $13(8.12)$ & $0.026^{\mathrm{b}}$ \\
Psychological discomfort & $16(10)$ & $25(15.62)$ & $0.132^{\mathrm{c}}$ \\
Physical disability & $19(11.87)$ & $31(19.37)$ & $0.065^{\mathrm{c}}$ \\
Psychological disability & $17(10.62)$ & $33(20.62)$ & $0.014^{\mathrm{b}}$ \\
Social disability & $18(11.25)$ & $4(2.5)$ & $0.002^{\mathrm{b}}$ \\
Handicap & $19(11.87)$ & $5(3.12)$ & $0.003^{\mathrm{b}}$
\end{tabular}

a Pearson's chi-squared test. $b \mathrm{p}<0.05$ is significant. c $p>0.05$ is not significant.

Table 4. Spearman's correlation coefficients between the variables of oral health status and OHIP-14 among tobacco factory workers

\begin{tabular}{lccccc} 
OHIP-14 & DMFT & DMFS & $\begin{array}{c}\text { Periodontal } \\
\text { Pocket }\end{array}$ & LOA \\
\hline Functional limitation & 0.513 & 0.584 & 0.485 & 0.498 \\
Physical pain & 0.611 & 0.622 & 0.406 & 0.561 \\
$\begin{array}{l}\text { Psychological } \\
\text { discomfort }\end{array}$ & 0.634 & 0.717 & 0.389 & 0.548 \\
Physical disability & 0.649 & 0.714 & 0.422 & 0.559 \\
Psychological disability & 0.640 & 0.699 & 0.436 & 0.573 \\
Social handicap & 0.646 & 0.718 & 0.433 & 0.558 \\
Handicap & 0.626 & 0.684 & 0.449 & 0.539
\end{tabular}

In all cases $\mathrm{p}<0.001$.
Table 5. Spearman's correlation coefficients between the variables of oral health status and OHIP-14 among cotton ginning mill workers

\begin{tabular}{|c|c|c|c|c|}
\hline OHIP-14 & DMFT & DMFS & $\begin{array}{c}\text { Periodontal } \\
\text { Pocket }\end{array}$ & LOA \\
\hline Functional limitation & 0.444 & 0.441 & 0.421 & 0.361 \\
\hline Physical pain & 0.543 & 0.560 & 0.468 & 0.487 \\
\hline $\begin{array}{l}\text { Psychological } \\
\text { discomfort }\end{array}$ & 0.645 & 0.648 & 0.532 & 0.498 \\
\hline Physical disability & 0.694 & 0.712 & 0.612 & 0.571 \\
\hline Psychological disability & 0.662 & 0.686 & 0.527 & 0.528 \\
\hline Social handicap & 0.189 & 0.216 & 0.257 & 0.225 \\
\hline Handicap & 0.650 & 0.664 & 0.568 & 0.534 \\
\hline
\end{tabular}

In all cases $\mathrm{p}<0.001$, except for Social handicap where $\mathrm{p}<0.01$.

The variables of oral health status among the workers in the two groups are compared and presented in Figure 1. No statistically significant differences were noted in the mean DMFT, mean DMFS and type of traumatic dental injuries between the two groups ( $p>0.05)$. The mean overall OHIP14 score was significantly higher among tobacco factory workers $(20.81 \pm 11.59)$ compared to cotton ginning mill workers $(16.29 \pm 9.67)$. The frequency of impact for each OHIP-14 domain between the workers in two groups is given in Table 3. All OHIP-14 domains were found to have a statistically significant positive correlation with DMFT, DMFS, periodontal pocket and loss of attachment in both tobacco factory and cotton ginning mill workers (Tables 4 and 5).

\section{DISCUSSION}

This study focused on the oral health status and oral health-related quality of life of tobacco factory workers and compared these with those of cotton ginning mill workers. 
The findings of the present study could not be compared with earlier studies as there is a paucity of literature on the oral health status of these populations. Hence, the findings of the present study have been compared with workers in other industries and general population.

The analysis of the demographic characteristics of the studied population revealed that females were equally employed in both factories as males. The reason for this could be the flexible working hours, giving women the opportunity to combine work with domestic responsibilities. Since the tobacco and cotton ginning industries are labour intensive and the monopoly demanded centralization to avoid fraud, a female workforce might be preferred ${ }^{11}$.

Tobacco use is one of the most important preventable causes of disease and death, globally. Even though the prevalence of tobacco use is declining in many countries, disparities among occupational groups still exist ${ }^{12}$. In the present study, the prevalence of smokeless tobacco use among tobacco factory workers was $38.1 \%$, which is significantly higher than $15 \%$ for cotton ginning mill workers. An explanation for this difference could be the easy access to smokeless tobacco among tobacco factory workers on a daily basis at their workplace. Previous research conducted by Kawatra et al. ${ }^{13}$ reported a prevalence of $45.97 \%$ tobacco chewers among tobacco industry workers in Maharashtra.

Among the workers using tobacco, the proportion of the workers who perceived the working environment as a barrier to quit their habits was found to be significantly higher among tobacco factory workers $(74.7 \%)$ compared to cotton ginning mill workers $(10.3 \%)$. This observation supports the fact that the motivation and skills to quit tobacco habits cannot be effective if the workers' environment makes it difficult or almost impossible to change their behaviour. This could also be the reason for the lower proportion of quitters among tobacco factory workers ${ }^{14}$.

In the present study, tobacco factory workers had a higher prevalence of periodontal pockets (47.5\%) and loss of attachment (56.9\%) compared to cotton ginning mill workers. The explanation for this difference could be the higher prevalence of smokeless tobacco use among tobacco factory workers, which is a potential risk factor for the development of periodontal pockets. Prevalence as high as $51 \%$ was reported for shallow pockets by Amjad et al. ${ }^{15}$ among tobacco chewers in Pakistan.

In the present study, tobacco-related oral mucosal lesions were seen only among tobacco factory workers. None of the cotton ginning mill workers exhibited tobaccorelated oral mucosal lesions. Among the oral mucosal lesions, the prevalence of tobacco pouch keratosis and leukoplakia were found to be $4.4 \%$ and $1.9 \%$, respectively, for the tobacco factory workers. This could be due to the higher prevalence of tobacco use in chewing form (38.1\%) than smoking form (25.6\%) among the workers. Also, it could be that it takes prolonged exposure to develop leukoplakia while tobacco pouch keratosis develops earlier due to local irritation caused by the placement of quid ${ }^{16}$.

The mean overall OHIP-14 scores among tobacco factory workers and cotton ginning mill workers were $20.81 \pm 11.59$ and $16.29 \pm 9.67$, respectively. Similar findings were reported in a previous study conducted among the adult population in Chennai17. The explanation for the higher OHIP-14 score among tobacco factory workers could be attributed to their poor oral health status compared to cotton ginning mill workers.

A limitation of this study is that the socioeconomic status of the study subjects was not taken into account, as they were paid on a daily basis, which varied widely, making it difficult to calculate their monthly income.

\section{CONCLUSIONS}

The prevalence of periodontal diseases, oral mucosal lesions, use of tobacco and the OHIP-14 scores were all found to be significantly higher among tobacco factory workers compared to cotton ginning mill workers. OHIP-14 scores were significantly correlated with clinical oral health status indicators among subjects in both study groups. Hence, when planning treatment strategies, including tobacco cessation counselling for these workers, depending on the availability of resources and manpower, priority has to be given to the tobacco factory workers, as potentially malignant disorders and treatment needs are greater among this group compared to the cotton ginning mill workers. Therefore, an integrated curative and prevention based approach along with behaviour change programs, directed especially towards tobacco cessation, are warranted to achieve optimum level of oral health among these workers.

\section{REFERENCES}

1. Britton J. Death, disease, and tobacco. Lancet. 2017;389(10082): 1861-1862. doi:10.1016/S0140-6736(17)30867-X

2. The Tobacco Institute of India. Factsheets: Tobacco production. https://www.tiionline.org/facts-sheets/tobaccoproduction/. Accessed April 4, 2018.

3. Burton J. WHO Healthy Workplace Framework and Model: Background and Supporting Literature and Practices. Geneva, Switzerland: World Health Organization; 2010. https://www. who.int/occupational_health/healthy_workplace_framework. pdf. Accessed April 6, 2018.

4. Petersen PE, Henmar P. Oral conditions among workers in the Danish granite industry. Scand J Work Environ Health. 1988;14(5):328-331. doi:10.5271/sjweh.1911

5. Masalin K, Murtomaa H, Meurman JH. Oral health of workers in the modern Finnish confectionery industry. Community Dent Oral Epidemiol. 1990;18(3):126-130. doi:10.1111/j.1600-0528.1990.tb00036.x

6. World Health Organization. Tobacco and its environmental impact: an overview. Geneva, Switzerland: World Health Organization; 2017. https://www.who.int/tobacco/ 
publications/environmental-impact-overview/en/. Accessed February 26, 2019.

7. Kakde S, Bedi R, Verma M. Oral health inequalities: a call for action to improve oral health in India. Int Dent J. 2013;63(6):324-328. doi:10.1111/idj.12048

8. Effat Khodadadi, Mina Motallebnejad and Mehnoosh Alizadeh. Oral health related quality of life among adults reffered to dental clinic of Babol Faculty of Dentistry in 20092011. Caspian Journal of Dental Research. 2013;2(1):53-60. doi:10.22088/cjdr.2.1.53

9. Slade GD. Derivation and validation of a short-form oral health impact profile. Community Dent Oral Epidemiol. 1997;25(4):284-290. doi:10.1111/j.1600-0528.1997.tb00941.x

10.World Health Organization. Oral health surveys: basic methods. Geneva, Switzerland: World Health Organization; 2013. http://apps.who.int/iris/bitstream/ handle/10665/97035/9789241548649_eng.pdf;jse ssionid=75FC8ADBFC51D435ADAF48A96AD41941? sequence=1. Accessed April 12, 2018.

11. Muñoz LG. Gender, Cigar and Cigarettes. Technological Change and National Patterns. In: XIV International Economic History Congress; 2006. http://www.helsinki.fi/iehc2006/ papers1/Galvez.pdf. Accessed February 26, 2019.

12. Pednekar M, Nagler E, Pawar P, Sorensen G, Narake S, Stoddard A. The prevalence of tobacco use among manufacturing workers: findings from the baseline survey of the Mumbai worksite tobacco control study. J Prev Med.
2015;1(1):3-7. doi:10.21767/2572-5483.100003

13. Kawatra A, Lathi A, Kamble SV, Sharma P, Parhar G. Oral premalignant lesions associated with areca nut and tobacco chewing among the tobacco industry workers in area of Rural Maharashtra. National Journal of Community Medicine. 2012;3(2):333-338. http://njcmindia.org/ uploads/3-2_333-338.pdf. Accessed February 26, 2019.

14. Calo WA, Krasny SE. Environmental determinants of smoking behaviors: The role of policy and environmental interventions in preventing smoking initiation and supporting cessation. Current cardiovascular risk reports. 2013;7(6):446-452. doi:10.1007/s12170-013-0344-7

15. Amjad F, Ali S, Umair M, Bhatti D, Chaudhry Au. Effects of Tobacco Chewing on Oral Health Status of Patients Visiting University College of Dentistry, Lahore. Pakistan Oral \& Dental Journal. 2012;32(3)489-492. https://pdfs.semanticscholar. org/9233/e8eb5c214edce03b85710fe6d8eb5191b69b.pdf. Accessed February 26, 2019.

16. Chitroda PK, Shah JT, Katti G, Ghali S. A Correlative Study of Smokeless Tobacco induced Lesion and Smoke-induced Leukoplakia in Various Aspects. Journal of Indian Academy of Oral Medicine and Radiology. 2011;23(2):86-90. doi:10.5005/jp-journals-10011-1101

17. Ingle NA, Chaly PE, Zohara CK. Oral health related quality of life in adult population attending the outpatient department of a hospital in Chennai, India. J Int Oral Health. 2010;2(4):45-56. doi:10.5005/johcd-9-1-30
ACKNOWLEDGEMENTS

The authors thank all the participants for their kind cooperation throughout the study.

CONFLICTS OF INTEREST

The authors have completed and submitted the ICMJE Form for Disclosure of Potential Conflicts of Interest and none was reported.

\section{FUNDING}

There was no source of funding for this research.

PROVENANCE AND PEER REVIEW

Not commissioned; externally peer reviewed. 